\title{
Época de Dessecação AnTerior à Semeadura sobre o Desenvolvimento da Soja Resistente ao Glyphosate ${ }^{1}$
}

\author{
Influence of Desiccation Time Before Sowing on the Development of Soybean Resistant to \\ Glyphosate
}

\author{
SANTOS, J.B. ${ }^{2}$, SANTOS, E.A. ${ }^{3}$, FIALHO, C.M.T. ${ }^{4}$, SILVA, A.A. ${ }^{5}$ e FREITAS, M.A.M. ${ }^{4}$
}

RESUMO - Com o presente trabalho, objetivou-se avaliar o melhor momento para dessecação de Brachiaria brizantha com glyphosate, visando a semeadura da soja geneticamente modificada, resistente a esse herbicida. Para isso, estabeleceram-se várias épocas de dessecação (2.880 $\mathrm{g} \mathrm{ha}^{-1}$ de glyphosate), variando de 21 a zero dias antes da semeadura da soja e com uma $\left(1.080 \mathrm{~g} \mathrm{ha}^{-1}\right)$ ou duas $\left(1.080+1.080 \mathrm{~g} \mathrm{ha}^{-1}\right)$ aplicações do glyphosate em pós-emergência da cultura, respectivamente aos 15 e 40 dias. Aos cinco dias após a primeira aplicação em pós-emergência e por ocasião do florescimento, foram avaliados o número e a massa seca de folíolos, massa seca do restante da parte aérea, de raízes e dos nódulos radiculares. Na mesma época, foram coletadas amostras do solo para determinação da taxa de respiração basal e biomassa microbiana (esta somente no florescimento). No final do ciclo, determinou-se o rendimento de grãos da soja em função dos diferentes tratamentos. As aplicações em pós-emergência do glyphosate afetaram o crescimento da soja, diminuindo a massa seca das plantas. Melhor desenvolvimento da soja foi observado quando se utilizou o glyphosate somente para dessecação, realizada entre 7 e 21 dias antes da semeadura. Maior impacto negativo na biomassa microbiana foi observado quando a dessecação e a semeadura foram realizadas no mesmo dia. O rendimento de grãos da cultura foi diminuído em mais de $40 \%$ na testemunha, sem aplicação do glyphosate, e, em média, $23 \%$ nas plantas que receberam o herbicida em pós-emergência.

Palavras-chave: atividade microbiana do solo, Brachiaria brizantha, quociente metabólico, respiração basal do solo.

\begin{abstract}
The objective of this paper was to evaluate the best timing for Brachiaria brizantha desiccation with glyphosate, aiming at transgenic soybean sowing. Different desiccation times

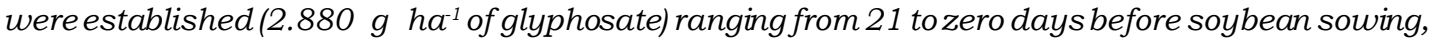
with one $\left(1.080 \mathrm{~g} \mathrm{ha}^{-1}\right)$ or two $\left(1.080+1.080 \mathrm{~g} \mathrm{ha}^{-1}\right)$ glyphosate applications in postemergence, respectively at 15 and 40 days. At five days after the first application and during flowering, foliate number and dry matter, dry matter of the remaining aerial part, roots, and radicular nodules were evaluated. During the same time, soil samples were collected to determine basal respiration rate and microbial biomass. At the end of the cycle, soybean grain yield was determined according to the different treatments. Soybean grouth was affected by postemergence application of glyphosate, decreasing plant dry matter. Soybean development improved when glyphosate was used for desiocation between 7 and 21 days before sowing. Higher negative impactagainst microbial biomass occurred when desiccation and sowing were performed at the same day. Without glyphosate application, control grain yield decreased in more than $40 \%$, and, on average, $23 \%$ on the plants that received the herbicide in postemergence.
\end{abstract}

Keywords: soil microbial activity, Brachiaria brizantha, metabolic quotient, soil basal respiration.

Recebido para publicação em 22.4.2007 e na forma revisada em 29.11.2007.

2 Professor de Agronomia da Universidade Vale do Rio Doce. Rua Israel Pinheiro, 2000, 35020-220, Caixa Postal 295 Governador Valadares-MG, <jbarbosa@univale.br>; ${ }^{3}$ Estudante de pós-graduação do Dep. de Fitotecnia da Universidade Federal de Viçosa (DFT/UFV); ${ }^{4}$ Acadêmicos do curso de Agronomia da UFV; ${ }^{5}$ Professor Associado do DFT/UFV, <aasilva@ufv.br>.

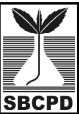

Planta Daninha, Viçosa-MG v. 25, n. 4, p. 869-875, 2007 


\section{INTRODUÇÃO}

A partir da introdução, na agricultura brasileira, de variedades de soja transgênicas geneticamente modificadas para resistência ao glyphosate, a utilização desse herbicida tem aumentado, principalmente quando empregado nas etapas de aplicação em pós-emergência.

Com os benefícios da utilização de um único produto para controle das plantas daninhas, o cultivo da soja transgênica tem se expandido para extensas áreas, inclusive em locais somente ocupados por pastagens. Essa leguminosa tem sido uma das principais alternativas para recuperação e renovação de pastagens degradadas; a rotação da soja com pastagem (dois a três anos) tem propiciado beneficios para ambas as culturas (Kichel et al., 2000). Espécies como Brachiaria brizantha contemplam mais de $50 \%$ do mercado nacional de forrageiras (Zimmer \& Euclides Filho, 1997), sendo uma das gramineas mais utilizadas nessa integração. Nesse sistema, a braquiária é dessecada com herbicidas de manejo, como o glyphosate, formando cobertura morta para o plantio direto da soja.

O glyphosate inibe a síntese dos aminoácidos aromáticos por atuar na enzima precursora EPSPs (5 enolpiruvilshiquimato-3-fosfato sintase), evitando a transformação do shiquimato em corismato (Shaner \& Bridges, 2003). No caso da soja resistente ao glyphosate, a tolerância ao herbicida foi obtida pela inserção de um gene (AroA) oriundo do genoma da Agrobacterium sp., estirpe CP4, a qual codifica uma variante da EPSPs (CP4 EPSPS), especialmente tolerante à inibição pelo glyphosate (Padgette et al., 1995). Sob tratamento com esse herbicida, as plantas de soja não são afetadas, em razão da ação continuada e sistemática dessa enzima alternativa, insensivel ao produto.

No entanto, tem sido relatado efeito do glyphosate prejudicando o desenvolvimento inicial de plantas de soja, para a qual esse produto é recomendado (Oliveira Jr., 2006; Silva et al., 2006). Esse efeito pode estar relacionado ao aumento demasiado da dose aplicada, ou do número de aplicações, ou ainda da época de aplicação. Segundo Oliveira Jr. (2006), as estratégias comumente utilizadas no manejo da vegetação infestante quanto à dessecação para plantio da soja em sistema de plantio direto resumem-se à dessecação imediatamente antes da semeadura, entre sete e dez dias antes da semeadura, ou à dessecação antecipada.

A interferência negativa do glyphosate sobre os microrganismos do solo e aqueles associados diretamente com as plantas (particularmente fungos formadores de micorrizas e fixadores de nitrogênio) vem sendo investigada (Kaps \& Kuhns, 1987; Edwards, 1989; Chakravarty \& Chatarpaul, 1990; Moorman \& Dowler, 1991; Santos et al., 2003, 2004; Silva et al., 2006). Acredita-se que a aplicação desse herbicida sobre alguns grupos que, no solo, desenvolvem papel importante, livres ou quando em simbioses com espécies vegetais, ajudaria a esclarecer os efeitos negativos observados no caso particular da soja transgênica.

Objetivou-se com este trabalho avaliar o desenvolvimento e a produção da soja resistente ao glyphosate em função da época de dessecação da braquiária para semeadura da soja com e sem aplicações em pós-emergência, bem como os efeitos sobre a atividade microbiana do solo.

\section{MATERIAL E MÉTODOS}

O experimento foi avaliado em casa de vegetação, pertencente ao Laboratório de Herbicidas no Solo do Departamento de Fitotecnia da UFV, adotando-se o delineamento experimental de blocos casualizados, com 13 tratamentos e seis ou nove repetições (a depender do tratamento - Tabela 1). Os tratamentos consistiram de diferentes épocas de dessecação da braquiária ( $B$. brizantha cultivar Marandu), variando de 21 a zero dias antes da semeadura da soja, e uma ou duas aplicações em pósemergência do glyphosate. A dose de glyphosate utilizada para dessecação de $B$. brizantha nas diferentes épocas foi de $2.880 \mathrm{~g} \mathrm{ha}^{-1}$ e, em pósemergência, de $1.440 \mathrm{~g} \mathrm{ha}^{-1}$, aos 15 e 40 dias após a emergência (DAE), conforme tratamentos especificados na Tabela 1.

$B$. brizantha foi cultivada em vasos contendo $6 \mathrm{dm}^{3}$ de solo previamente caracterizados química e fisicamente, sendo corrigidas a acidez e a fertilidade. Ela foi semeada a intervalos de sete dias, de forma que a dessecação 
Tabela 1 - Relação dos tratamentos propostos para estudo do efeito da dessecação de Brachiaria brizantha com glyphosate sobre o desenvolvimento da soja transgênica e atividade da microbiota do solo

\begin{tabular}{|c|c|c|}
\hline Tratamento $^{1 /}$ & $\begin{array}{l}\text { Época de aplicação do glyphosate (dias) para dessecação de Brachiaria } \\
\text { brizantha c/ou cm pós-emergência da soja resistente a esse herbicida }\end{array}$ & $\begin{array}{l}\text { Número de } \\
\text { repetições }\end{array}$ \\
\hline 01 & Pré (21) & 09 \\
\hline 02 & Pré (14) & 09 \\
\hline 03 & Pré (7) & 09 \\
\hline 04 & Pré $(0)$ & 09 \\
\hline 05 & Pré $(21)+$ pós $(15)$ & 09 \\
\hline 06 & Pré (14) + pós (15) & 09 \\
\hline 07 & Pré (7) + pós (15) & 09 \\
\hline 08 & Pré $(0)^{*}+$ pós (15) & 09 \\
\hline 09 & Pré (21) + pós (15 e 40) & 06 \\
\hline 10 & Pré (14) + pós (15 e 40) & 06 \\
\hline 11 & Pré $(7)+$ pós $(15$ e 40$)$ & 06 \\
\hline 12 & Pré $(0)^{*}+$ pós $(15$ e 40$)$ & 06 \\
\hline 13 & Sem herbicidas & 09 \\
\hline
\end{tabular}

11 $01,02,03$ e 04 - glyphosate $\left(2.880 \mathrm{~g} \mathrm{ha}^{-1}\right)$ aplicado aos 21,14 e 7 dias antes da semeadura e no momento desta, respectivamente; 05 , 06, 07 e 08 - glyphosate $\left(2.880 \mathrm{~g} \mathrm{ha}^{-1}\right)$ aplicado aos 21,14 e 7 dias antes da semeadura e no momento desta, respectivamente, mais uma aplicação $\left(1.080 \mathrm{~g} \mathrm{ha}^{-1}\right)$ em pós-emergência aos $15 \mathrm{DAE}$; 09, 10, 11 e 12 - glyphosate $\left(2.880 \mathrm{~g} \mathrm{ha}^{-1}\right)$ aplicado aos $21,14 \mathrm{e} 7$ dias antes da semeadura e no momento desta, respectivamente, mais duas aplicações $\left(1.080 \mathrm{~g} \mathrm{ha}^{-1}\right)$ em pós-emergência aos $15 \mathrm{e} 40 \mathrm{DAE}$, respectivamente; 13 - tratamento sem cultivo prévio de B. brizantha e sem aplicação de herbicidas (testemunha).

* Plantio e aplicação no mesmo dia.

ocorresse aos $0,7,14$ ou 21 dias antes da semeadura da soja, que foi em única época.

A dessecação química foi feita empregando-se pulverizador costal de precisão, utilizando-se bico TT110.02, à pressão constante de $3,0 \mathrm{kgf} \mathrm{cm}^{-2}$, aplicando-se o equivalente a $100 \mathrm{~L} \mathrm{ha}^{-1}$ de calda.

Foram semeadas quatro sementes por vaso, sendo posteriormente realizado o desbaste, deixando-se duas plântulas. As sementes de soja, variedade CD 219RR, contendo o gene CP4EPSPS, tolerante ao glyphosate, foram mergulhadas em meio com mistura de quatro estirpes de Bradyrhizobium (SEMIA 5019, SEMIA 5079, SEMIA 5080 e SEMIA 587), em fase ativa de crescimento. A unidade experimental foi representada por um vaso com duas plantas de soja.

Aos cinco dias após a primeira aplicação em pós-emergência (15 DAE), foram avaliados o número de massa seca de foliolos, massa seca do restante da parte aérea, de raízes e dos nódulos radiculares, por meio da coleta de três vasos/repetições dos tratamentos passiveis de comparação (tratamentos 1 ao 8 e 13; para os demais tratamentos a comparação dependia da segunda aplicação do herbicida em pósemergência - Tabela 1). Na mesma época, foram coletadas amostras do solo para determinação da taxa de respiração basal. Na etapa do florescimento, além das avaliações já mencionadas, a partir da coleta de outros três vasos/repetições, avaliou-se o carbono total da biomassa microbiana e o quociente metabólico. No final do ciclo, a partir do restante das repetições, determinou-se o rendimento de grãos da soja para os diferentes tratamentos.

Para avaliação da taxa de respiração basal do solo (quantidade de $\mathrm{CO}_{2}$ evoluído), amostras de $100 \mathrm{~g}$ do solo foram coletadas em cada vaso, o qual foi capturado em frascos contendo $100 \mathrm{~mL}$ de $\mathrm{NaOH}\left(0,25 \mathrm{~mol} \mathrm{~L}^{-1}\right)$, em sistema contínuo de fluxo de ar (isento de $\mathrm{CO}_{2}$ e umidade). As amostras de solo, após serem passadas por peneira com malha de 2 mesh e secas ao ar e ser determinado o teor de água, foram pesadas e incubadas por sete dias em erlenmeyer com teor de água a $70 \%$ da capacidade de campo. Após incubação por 10 dias, procedeuse à titulação indireta do hidróxido de sódio com $\mathrm{HCl}\left(0,25 \mathrm{~mol} \mathrm{~L}^{-1}\right)$, e o excesso de $\mathrm{NaOH}$ 
que não reagiu com o $\mathrm{CO}_{2}$ evoluído foi quantificado (Anderson, 1982).

No final do período de incubação das amostras de solos provenientes da época do florescimento das plantas de soja, determinou-se o carbono da biomassa microbiana (CBM) pelo método descrito por Vance et al. (1987), utilizando-se, em lugar do clorofórmio (fumigação), forno de microondas (irradiação) (Islam \& Weil, 1998), e o quociente metabólico $\left(\mathrm{qCO}_{2}\right)$, por meio da relação entre o $\mathrm{CO}_{2}$ acumulado $\left(\mu \mathrm{g} \mathrm{g}^{-1}\right)$ e o $\mathrm{C}$ total da biomassa microbiana ( $\mu \mathrm{g} \mathrm{g}^{-1}$ ).

Os dados foram submetidos à análise de variância, sendo as médias dos tratamentos, quando significativas, comparadas pelo teste de Tukey a $5 \%$ de probabilidade.

\section{RESULTADOS E DISCUSSÃO}

As aplicações em pós-emergência do glyphosate afetaram o crescimento da soja, sendo observada, cinco dias após a primeira aplicação, diminuição da massa seca das plantas (Tabela 2). Nessa etapa, não se observou efeito da época de dessecação sobre a taxa de des- prendimento de $\mathrm{CO}_{2}$ das amostras do solo coletadas, ficando a média diária em $0,218 \mathrm{mg} \mathrm{g}^{-1}$ de solo (Tabela 2). As características altura de plantas e número de folíolos não foram afetadas pelos tratamentos.

$\mathrm{Na}$ etapa do florescimento, melhor resultado para desenvolvimento da soja foi observado quando se utilizou o glyphosate somente para dessecação, realizada entre 7 e 21 dias antes da semeadura. As aplicações em pós-emergência afetaram a massa seca das plantas, sendo isso mais sentido nas raizes (Tabela 3 ). Independentemente da época de aplicação do herbicida em pós-emergência, a dessecação e plantio no mesmo dia afetou negativamente a massa seca de raízes. Nesse sentido, os menores valores de biomassa radicular foram observados nos tratamentos em que houve a dessecação e plantio no mesmo dia, seguida pelas aplicações em pós-emergência, sendo esse efeito atribuído ao herbicida. Também na testemunha - plantas de soja que não receberam aplicação de herbicida - a massa seca de plantas foi severamente reduzida, mas pelo efeito de competição com as espécies de plantas daninhas que emergiram nos vasos (Tabela 3 ).

Tabela 2 - Número de folíolos, altura e biomassa seca da parte aérea e de raiz e $\mathrm{CO}_{2}$ proveniente de amostras do solo da rizosfera de plantas de soja resistente ao glyphosate aplicado em diferentes condições. Avaliação realizada 20 dias após a emergência das plantas

\begin{tabular}{|c|c|c|c|c|c|}
\hline \multirow{2}{*}{ Tratamento $^{1 /}$} & \multicolumn{5}{|c|}{ Características avaliadas } \\
\cline { 2 - 6 } & $\begin{array}{c}\text { Folíolos por } \\
\text { planta }\end{array}$ & $\begin{array}{c}\text { Altura de plantas } \\
(\mathrm{cm})\end{array}$ & $\begin{array}{c}\text { Massa seca da } \\
\text { parte aérea }(\mathrm{g})\end{array}$ & $\begin{array}{c}\text { Massa seca de } \\
\text { raizes }(\mathrm{g})\end{array}$ & $\begin{array}{c}\mathrm{CO}_{2} \\
\left(\mathrm{mg} \mathrm{g}^{-1} \text { solo }^{-1} \mathrm{dia}^{-1}\right)\end{array}$ \\
\hline 01 & $9,50 \mathrm{a}^{\underline{2} /}$ & $20,25 \mathrm{a}$ & $0,617 \mathrm{a}$ & $1,750 \mathrm{a}$ & $0,240 \mathrm{a}$ \\
\hline 02 & $10,67 \mathrm{a}$ & $20,50 \mathrm{a}$ & $0,767 \mathrm{a}$ & $1,773 \mathrm{a}$ & $0,192 \mathrm{a}$ \\
\hline 03 & $10,50 \mathrm{a}$ & $20,50 \mathrm{a}$ & $0,850 \mathrm{a}$ & $1,896 \mathrm{a}$ & $0,267 \mathrm{a}$ \\
\hline 04 & $10,50 \mathrm{a}$ & $18,83 \mathrm{a}$ & $0,766 \mathrm{a}$ & $1,420 \mathrm{ab}$ & $0,255 \mathrm{a}$ \\
\hline 05 & $9,50 \mathrm{a}$ & $19,08 \mathrm{a}$ & $0,390 \mathrm{~b}$ & $1,426 \mathrm{ab}$ & $0,196 \mathrm{a}$ \\
\hline 06 & $9,50 \mathrm{a}$ & $21,33 \mathrm{a}$ & $0,337 \mathrm{~b}$ & $1,506 \mathrm{ab}$ & $0,153 \mathrm{a}$ \\
\hline 07 & $9,67 \mathrm{a}$ & $20,00 \mathrm{a}$ & $0,407 \mathrm{~b}$ & $1,310 \mathrm{~b}$ & $0,239 \mathrm{a}$ \\
\hline 08 & $8,33 \mathrm{a}$ & $22,00 \mathrm{a}$ & $0,287 \mathrm{c}$ & $1,223 \mathrm{~b}$ & $0,182 \mathrm{a}$ \\
\hline 13 & $8,33 \mathrm{a}$ & $15,50 \mathrm{a}$ & $0,377 \mathrm{~b}$ & $1,026 \mathrm{~b}$ & $0,239 \mathrm{a}$ \\
\hline $\mathrm{CV}(\%)$ & 8,52 & 9,50 & 11,99 & 8,22 & 18,58 \\
\hline
\end{tabular}

If $01,02,03$ e 04 - glyphosate $\left(2.880 \mathrm{~g} \mathrm{ha}^{-1}\right)$ aplicado aos 21,14 e 7 dias antes da semeadura e no momento desta, respectivamente; 05 , 06, 07 e 08 - glyphosate $\left(2.880 \mathrm{~g} \mathrm{ha}^{-1}\right)$ aplicado aos 21,14 e 7 dias antes da semeadura e no momento desta, respectivamente, mais uma aplicação $\left(1.080 \mathrm{~g} \mathrm{ha}^{-1}\right)$ em pós-emergência aos $15 \mathrm{DAE}$; 09, 10, 11 e 12 - glyphosate $\left(2.880 \mathrm{~g} \mathrm{ha}^{-1}\right)$ aplicado aos $21,14 \mathrm{e} 7$ dias antes da semeadura e no momento desta, respectivamente, mais duas aplicações $\left(1.080 \mathrm{~g} \mathrm{ha}^{-1}\right)$ em pós-emergência aos $15 \mathrm{e} 40 \mathrm{DAE}$, respectivamente; 13 - tratamento sem cultivo prévio de B. brizantha e sem aplicação de herbicidas (testemunha).

${ }^{2 /}$ Médias seguidas por letras iguais, em cada coluna, não diferem entre si pelo teste de Tukey a 5\% de probabilidade. 
Tabela 3 - Número e massa seca de folíolos, altura e biomassa seca do restante da parte aérea, de raízes e de nódulos radiculares de plantas de soja resistente ao glyphosate aplicado em diferentes condições. Avaliação realizada no florescimento, 65 dias após a emergência das plantas

\begin{tabular}{|c|c|c|c|c|c|}
\hline \multirow{3}{*}{ Tratamento $^{1 /}$} & \multicolumn{5}{|c|}{ Características avaliadas } \\
\hline & $\begin{array}{c}\text { Folíolos por } \\
\text { planta }\end{array}$ & $\begin{array}{c}\text { Massa seca de } \\
\text { folíolos }\end{array}$ & $\begin{array}{c}\text { Massa seca da } \\
\text { parte aérea }\end{array}$ & $\begin{array}{c}\text { Massa seca de } \\
\text { raízes }\end{array}$ & $\begin{array}{c}\text { Massa seca de } \\
\text { nódulos }\end{array}$ \\
\hline & $---n^{0}---$ & ---------------------- & -------------------. & |------------------ & ------------------- \\
\hline 01 & $39,33 \mathrm{a}^{2 /}$ & 6,98 a & $6,52 \mathrm{a}$ & $12,75 \mathrm{a}$ & $0,433 \mathrm{a}$ \\
\hline 02 & $38,67 \mathrm{a}$ & $7,18 \mathrm{a}$ & $6,22 \mathrm{a}$ & $13,24 \mathrm{a}$ & $0,398 \mathrm{a}$ \\
\hline 03 & $32,67 \mathrm{a}$ & 7,13 a & $6,60 \mathrm{a}$ & $12,08 \mathrm{a}$ & $0,458 \mathrm{a}$ \\
\hline 04 & $35,67 \mathrm{a}$ & 6,09 a & $5,83 \mathrm{a}$ & $8,55 \mathrm{~b}$ & $0,206 \mathrm{~b}$ \\
\hline 05 & $30,00 \mathrm{a}$ & $4,40 \mathrm{~b}$ & $3,86 \mathrm{~b}$ & $7,32 \mathrm{~b}$ & $0,219 \mathrm{~b}$ \\
\hline 06 & $34,00 \mathrm{a}$ & $5,79 a b$ & $4,95 \mathrm{ab}$ & $6,89 \mathrm{~b}$ & $0,213 \mathrm{~b}$ \\
\hline 07 & $34,66 \mathrm{a}$ & $4,62 \mathrm{~b}$ & $4,37 \mathrm{~b}$ & $8,52 \mathrm{~b}$ & $0,199 \mathrm{~b}$ \\
\hline 08 & $35,33 \mathrm{a}$ & $4,66 \mathrm{~b}$ & $4,43 \mathrm{~b}$ & $4,45 \mathrm{c}$ & $0,235 \mathrm{~b}$ \\
\hline 09 & 29,00 a & $3,60 \mathrm{~b}$ & $3,60 \mathrm{~b}$ & $5,11 \mathrm{c}$ & $0,244 \mathrm{~b}$ \\
\hline 10 & 29,33 a & $4,22 \mathrm{~b}$ & $3,91 \mathrm{~b}$ & $6,32 \mathrm{bc}$ & $0,218 \mathrm{~b}$ \\
\hline 11 & 38,33 a & $4,67 \mathrm{~b}$ & $4,21 \mathrm{~b}$ & $8,64 \mathrm{~b}$ & $0,223 \mathrm{~b}$ \\
\hline 12 & $30,33 \mathrm{a}$ & $4,03 \mathrm{~b}$ & $4,13 \mathrm{~b}$ & $5,95 \mathrm{bc}$ & $0,189 \mathrm{~b}$ \\
\hline 13 & $22,00 \mathrm{a}$ & $2,15 \mathrm{c}$ & $2,36 \mathrm{c}$ & $4,16 \mathrm{c}$ & $0,021 \mathrm{c}$ \\
\hline CV $(\%)$ & 17,55 & 12,45 & 7,52 & 11,33 & 27,00 \\
\hline
\end{tabular}

11 $01,02,03$ e 04 - glyphosate $\left(2.880 \mathrm{~g} \mathrm{ha}^{-1}\right)$ aplicado aos $21,14,7$ dias antes da semeadura e no momento desta, respectivamente; 05 , 06, 07 e 08 - glyphosate $\left(2.880 \mathrm{~g} \mathrm{ha}^{-1}\right)$ aplicado aos 21,14 e 7 dias antes da semeadura e no momento desta, respectivamente, mais uma aplicação $\left(1.080 \mathrm{~g} \mathrm{ha}^{-1}\right)$ em pós-emergência aos $15 \mathrm{DAE}$; 09, 10, 11 e 12 - glyphosate $\left(2.880 \mathrm{~g} \mathrm{ha}^{-1}\right)$ aplicado aos $21,14 \mathrm{e} 7$ dias antes da semeadura e no momento desta, respectivamente, mais duas aplicações $\left(1.080 \mathrm{~g} \mathrm{ha}^{-1}\right)$ em pós-emergência aos $15 \mathrm{e} 40 \mathrm{DAE}$, respectivamente; 13 - tratamento sem cultivo prévio de $B$. brizantha e sem aplicação de herbicidas (testemunha).

2 Médias seguidas por letras iguais, em cada coluna, não diferem entre si pelo teste de Tukey a $5 \%$ de probabilidade.

Efeito negativo da aplicação em pós-emergência do glyphosate sobre as plantas de soja também foi observado para acúmulo de massa seca de nódulos radiculares. Maior valor para massa seca nodal foi observado nos tratamentos em que o glyphosate somente foi aplicado visando a dessecação, entre 7 e 21 dias antes da semeadura (Tabela 3).

A microbiota do solo associado ao sistema radicular da soja apresentou carbono total diminuído somente nos tratamentos em que se realizou a dessecação no mesmo dia da semeadura da soja (tratamentos 4, 8 e 12). Esses resultados sugerem que a rizosfera da planta de soja é afetada quando o seu desenvolvimento é simultâneo à decomposição das raízes da braquiária. É provável que, ao se decompor, a braquiária libere, no entorno das raízes, substâncias que impeçam a associação dos micror- ganismos às raízes de soja recém-formadas. Ou, ainda, parte do glyphosate aplicado, que seria liberado pela decomposição das plantas, e ainda não adsorvido ao solo poderia estar afetando diretamente os microrganismos que se associariam à soja. Esse mesmo fato não ocorreu nos tratamentos com intervalo entre a dessecação da braquiária e a semeadura da soja, haja vista a tendência de aumento do carbono da biomassa microbiana à medida que se aumenta o tempo entre dessecação da graminea e semeadura da soja (Tabela 4). Silva et al. (2006) verificaram decréscimo na colonização micorrizica e no volume das raízes de plantas da soja convencional (não resistente ao herbicida) quando o glyphosate foi utilizado para dessecação sete dias antes do plantio da leguminosa. Os autores atribuíram o efeito negativo da dessecação à possível exsudação pelas plantas de $B$. brizantha. 
Tabela 4 - Taxa diária de respiração basal do solo $\left(\mathrm{CO}_{2}\right)$, carbono total da biomassa microbiana (CBM) e o quociente metabólico que relaciona ambos, em amostras de solo coletadas por ocasião do florescimento de plantas de soja resistente ao glyphosate aplicado em diferentes condições. Ao final do ciclo: rendimento de grãos dessa cultura

\begin{tabular}{|c|c|c|c|c|}
\hline \multirow{2}{*}{ Tratamento $^{1 /}$} & \multicolumn{4}{|c|}{ Características avaliadas } \\
\cline { 2 - 5 } & $\mathrm{CO}_{2}\left(\mathrm{mg} \mathrm{g}^{-1}\right.$ solo $\left.^{-1}\right)$ & $\mathrm{CBM}\left(\mathrm{mg} \mathrm{g}^{-1}\right.$ solo $\left.^{-1}\right)$ & $\mathrm{qCO}^{2}\left(\mathrm{CO}_{2} \mathrm{CBM}^{-1}\right)$ & Rendimento da soja $(\%)$ \\
\hline 01 & $0,217 \mathrm{a}^{2 /}$ & $16,09 \mathrm{a}$ & $0,013 \mathrm{a}$ & $99,33 \mathrm{a}$ \\
\hline 02 & $0,192 \mathrm{a}$ & $16,84 \mathrm{a}$ & $0,012 \mathrm{ab}$ & $100,0 \mathrm{a}$ \\
\hline 03 & $0,181 \mathrm{a}$ & $13,18 \mathrm{ab}$ & $0,014 \mathrm{ab}$ & $92,35 \mathrm{a}$ \\
\hline 04 & $0,173 \mathrm{a}$ & $9,17 \mathrm{~b}$ & $0,019 \mathrm{~b}$ & $89,14 \mathrm{ab}$ \\
\hline 05 & $0,208 \mathrm{a}$ & $16,42 \mathrm{a}$ & $0,013 \mathrm{ab}$ & $77,23 \mathrm{~b}$ \\
\hline 06 & $0,192 \mathrm{a}$ & $17,66 \mathrm{a}$ & $0,011 \mathrm{ab}$ & $78,54 \mathrm{~b}$ \\
\hline 07 & $0,177 \mathrm{a}$ & $14,05 \mathrm{a}$ & $0,013 \mathrm{ab}$ & $78,33 \mathrm{~b}$ \\
\hline 08 & $0,180 \mathrm{a}$ & $8,41 \mathrm{~b}$ & $0,021 \mathrm{~b}$ & $77,08 \mathrm{~b}$ \\
\hline 09 & $0,133 \mathrm{a}$ & $15,45 \mathrm{a}$ & $0,009 \mathrm{a}$ & $78,69 \mathrm{~b}$ \\
\hline 10 & $0,135 \mathrm{a}$ & $17,09 \mathrm{a}$ & $0,008 \mathrm{a}$ & $77,56 \mathrm{~b}$ \\
\hline 11 & $0,153 \mathrm{a}$ & $13,00 \mathrm{ab}$ & $0,012 \mathrm{ab}$ & $73,87 \mathrm{~b}$ \\
\hline 12 & $0,152 \mathrm{a}$ & $9,89 \mathrm{~b}$ & $0,015 \mathrm{ab}$ & $56,32 \mathrm{c}$ \\
\hline 13 & $0,141 \mathrm{a}$ & $15,90 \mathrm{a}$ & $0,009 \mathrm{a}$ & 11,33 \\
\hline $\mathrm{CV}(\%)$ & 17,55 & 14,45 & 7,52 & \\
\hline
\end{tabular}

11 $01,02,03$ e 04 - glyphosate $\left(2.880 \mathrm{~g} \mathrm{ha}^{-1}\right)$ aplicado aos $21,14,7$ dias antes da semeadura e no momento desta, respectivamente, 05 , 06, 07 e 08 - glyphosate $\left(2.880 \mathrm{~g} \mathrm{ha}^{-1}\right)$ aplicado aos 21,14 e 7 dias antes da semeadura e no momento desta, respectivamente, mais uma aplicação $\left(1.080 \mathrm{~g} \mathrm{ha}^{-1}\right)$ em pós-emergência aos $15 \mathrm{DAE}$; 09, 10, 11 e 12 - glyphosate $\left(2.880 \mathrm{~g} \mathrm{ha}^{-1}\right)$ aplicado aos $21,14 \mathrm{e} 7$ dias antes da semeadura e no momento desta, respectivamente, mais duas aplicações $\left(1.080 \mathrm{~g}^{\text {ha }}{ }^{-1}\right)$ em pós-emergência aos 15 e $40 \mathrm{DAE}$, respectivamente; 13 - tratamento sem cultivo prévio de B. brizantha e sem aplicação de herbicidas (testemunha).

$\supseteq$ Médias seguidas por letras iguais, em cada coluna, não diferem entre si pelo teste de Tukey a 5\% de probabilidade.

Quando se avalia a estabilidade do solo por meio da relação entre $\mathrm{CO}_{2}$ liberado e biomassa microbiana produzida $\left(\mathrm{qCO}_{2}\right)$, é possivel estimar qual tratamento causa maior desequilibrio na dinâmica dos microrganis mos do solo (Tótola \& Chaer, 2002). Os microrganismos do solo, quando estressados, tendem a diminuir o aproveitamento de carbono que deveria ser reincorporado ao metabolismo. Dessa forma, considerando que menores valores de $\mathrm{qCO}_{2}$ indicam maior eficiência da biomassa, os tratamentos que promoveram menor efeito negativo à microbiota do solo foram: testemunha, seguido pela dessecação aos 14 e 21 dias antes da semeadura e duas aplicações em pósemergência, diferindo dos tratamentos dessecação e plantio no mesmo dia, os quais apresentaram maiores valores de $\mathrm{qCO}_{2}$ (Tabela 4). Entre os demais tratamentos não se observou diferença nessa característica. Valores elevados de $\mathrm{qCO}_{2}$ podem ser explicados pela diminuição da diversidade microbiana, o que contribui para diminuição da redundância funcional dos microrganismos no solo. Mader et al. (2002), avaliando agroecossistemas por mais de 20 anos, observaram alta correlação negativa entre $\mathrm{qCO}_{2}$ e diversidade microbiana.

O rendimento de grãos da cultura foi diminuído em mais de $40 \%$ na testemunha, sem aplicação do glyphosate, sendo esse fato atribuído à maior competição com as plantas daninhas presentes durante o periodo de desenvolvimento da cultura. Nos tratamentos que receberam aplicação em pós-emergência do herbicida, a redução no rendimento de grãos foi, em média, de 23\% (Tabela 4). Em trabalho realizado por Oliveira Júnior (2006), a dessecação realizada na data da semeadura - sistema conhecido como "aplique e plante" - ou dez dias antes prejudicou o desenvolvimento da soja, resultando em queda na produtividade, quando comparado ao manejo antecipado de aproximadamente 20 dias para a semeadura. 
A partir dos resultados, é possivel concluir que a dessecação e semeadura da soja no mesmo dia, além de afetar o desenvolvimento da cultura, promove efeito negativo na atividade de microrganismos do solo. O intervalo entre dessecação e semeadura da soja resistente ao glyphosate deve ser de, pelo menos, sete dias; aplicações em pós-emergência somente serão recomendadas se necessário, levando-se em consideração as plantas daninhas infestantes e a real necessidade do controle químico.

\section{AGRADECIMENTOS}

Ao Conselho Nacional de Desenvolvimento Científico e Tecnológico (CNPq), pelo apoio financeiro, e à Coodetec, pelo fornecimento das sementes de soja para realização deste trabalho.

\section{LITERATURA CITADA}

ANDERSON, J. P. E. Soil respiration. In: PAGE, A. L.; MILLER, R. H.; KEENEY, D. R. (Eds.). Methods of soil analysis - Part 2 - Chemical and microbiological properties. Madison: America Society of Agronomy, 1982. v. 2, p. 831871.

CHAKRAVARTY, P.; CHATARPAUL, L. Non-target effect of herbicides: II. The influence of glyphosate on ectomycorrhizal symbiosis of red pine (Pinus resinosa) under greenhouse and field conditions. Pest. Sci., v. 28, p. $243-247,1990$.

EDWARDS, C. A. Impact of herbicides on soil ecosystems. Crit. Rev. Plant Sci., v. 8, p. 221-257, 1989.

ISLAM, K. R.; WEIL, R. R. Microwave irradiation of soil for routine measurement of microbial biomass carbon. Biol. Fert. Soils, v. 27, p. 408-416, 1998.

KAPS, M. A.; KUHNS, L. J. Glyphosate transfer between plants via mycorrhizal fungi. HortSicence, v. 22, n. 5 , p. 652, 1987.

KICHEL, A. N.; MIRANDA, C. H. B.; TAMBOSI, S. A. T. Produção de bovinos de corte com a integração agricultura $\mathrm{x}$ pecuária. In: SIMPÓSIO DE FORRAGICULTURA E PASTAGENS: TEMAS EM EVIDÊNCIAS, 1., 2000, Lavras. Anais... Lavras: Universidade Federal de Lavras, 2000. p. 51-68.
MADER, P. et al. Soil fertility and biodiversity in organic farming. Sci., v. 296, p. 4, 2002.

MOORMAN, T. B.; DOWLER, C. C. Herbicide and rotation effects on soil and rhizosphere microorganisms and crop yields. Agric. Ecosyst. Environ., v. 35, p. 311-325, 1991.

OLIVEIRA JÚNIOR, R. S. et al. Interação entre sistemas de manejo e de controle de plantas daninhas em pós-emergência afetando o desenvolvimento e a produtividade da soja.

Planta Daninha, v. 24, p. 721-732, 2006.

PADGETTE, S. R. et al. New weed control opportunities: development of glyphosate-tolerant soybeans. In: DUKE, S. O. (Ed.) Herbicide resistant crops. Boca Raton: CRC, 1995. p.54-80.

SANTOS, J. B. et al. Comportamento de estirpes de Bradyrhizobium sp. sob efeito de componentes do glyphosate potássico. R. Ci. Agron., v. 34, n. 2, p. 201-206, 2003.

SANTOS, J. B. et al. Efeitos de diferentes formulações comerciais de glyphosate sobre estirpes de Bradyrhizobium. Planta Daninha, v. 22, n. 2, p. 293-299, 2004.

SHANER, D.; BRIDGES, D. Inhibitors of aromatic amino acid biosyntesis (glyphosate). In: Herbicide action course. West Lafayette: Purdue University, 2003. p. 514-529.

SILVA, A.C. et al. Micorrização e épocas de dessecação de Brachiaria brizantha no desenvolvimento da soja. Planta Daninha, v. 24, p. 271-277, 2006.

TÓTOLA, M. R.; CHAER, G. M. Microrganismos e processos microbiológicos como indicadores da qualidade dos solos. VENEGAS, V. H. A. et al. (Eds.). Tópicos em ciência do solo. Viçosa, MG: Sociedade Brasileira de Ciência do Solo, 2002. v. 2, p.195-276.

VANCE, E. D.; BROOKES, P. C.; JENKINSON, D. S. An extraction method for measuring soil microbial biomass $\mathrm{C}$. Soil Biol. Biochem., v. 19, p. 703-707, 1987.

ZIMMER, A. H.; EUCLIDES FILHO, K. As pastagens e a pecuária de corte brasileira. In: SIMPÓSIO

INTERNACIONAL SOBRE PRODUÇÃO ANIMAL EM PASTEJO, 1997, Viçosa. Anais...Viçosa, MG: 1997. p. 349379. 